\title{
Rare expression of BSAP (PAX-5) in mature T-cell lymphomas
}

\author{
Alexandar S Tzankov ${ }^{1}$, Philip T Went ${ }^{1}$, Simone Münst ${ }^{1}$, Thomas Papadopoulos ${ }^{2}$, \\ Gernot Jundt ${ }^{1}$ and Stephan R Dirnhofer ${ }^{1}$ \\ ${ }^{1}$ Institute of Pathology and Bone Tumor Reference Center, University Hospital Basel, Basel, Switzerland and \\ ${ }^{2}$ Institute of Pathology, University of Erlangen, Erlangen, Germany
}

\begin{abstract}
Lineage determination in lymphomas is based on the assessment of lineage-specific markers, such as the B-cell-specific activator protein of the paired box family (BSAP, PAX-5) for the B-cell lineage. BSAP is thought to be expressed exclusively in $B$ cells from the pro-B- to the mature B-cell stage and then silenced in plasma cells. BSAP has oncogenic potential and experimental evidence shows that the T-cell lineage is prone to this effect. Herein, we report on a BSAP-positive peripheral T-cell lymphoma with monoclonal $T$-cell receptor $\gamma$-gene rearrangement. To assess the relative frequency of BSAP expression in mature T-cell lymphomas, we constructed and examined a tissue microarray consisting of $\mathbf{4 3}$ angioimmunoblastic T-cell lymphomas and peripheral T-cell lymphomas and detected no additional BSAP-positive cases. To conclude, BSAP can probably contribute to T-cell lymphomagenesis not only in vitro, but also in vivo. It is rarely expressed in peripheral T-cell lymphoma, thus its detection on lymphoid malignancies cannot be considered definitively lineage specific. Modern Pathology (2007) 20, 632-637; doi:10.1038/modpathol.3800778; published online 13 April 2007
\end{abstract}

Keywords: BSAP; PAX-5; peripheral T-cell lymphoma; angioimmunoblastic T-cell lymphoma

Lineage and maturity determination as well as exact classification of lymphoid malignancies has a major impact on proper patient management, particularly on the choice of therapy. ${ }^{1}$ Lineage determination in lymphomas is based on the expression analysis of lineage-specific, primarily surface- and cytoplasmic, markers, such as CD2, CD3 and CD5 for the T-cell lineage and CD19, CD20, CD22 and CD79a, as well as the nuclear marker B-cell-specific activator protein (BSAP, PAX-5), for the B-cell lineage..$^{2,3}$ BSAP is a transcription factor of the paired box (PAX) family that regulates B-cell commitment and maintains B-cell functional identity. It is thought to be expressed within the hematopoietic system almost exclusively from the pro-B- to the mature lympho-plasmocytoid B-cell stage and to be silenced in plasma cells. ${ }^{3-6}$ In the T-cell lineage, BSAP completely blocks cellular development by repressing the T-cell-specification gene Notch $1 .^{7}$ In addition to hematological neoplasms, BSAP is expressed, and displays its oncogenic potential, in bladder carcinomas, neuroendocrine tumors and

Correspondence: Dr AS Tzankov, MD, Institute of Pathology and Bone Tumor Reference Center, University Hospital Basel, Schoenbeinstr 40, CH-4031 Basel, Switzerland.

E-mail: atzankov@uhbs.ch

Received 22 January 2007; revised and accepted 20 February 2007; published online 13 April 2007 astrocytomas, in all of which its presence parallels morphological and/or clinical aggressiveness. ${ }^{8-11}$

'Lineage infidelity' of surface/cytoplasmic markers is a well-documented phenomenon in human tumors in general and lymphomas in particular, and although its biological mechanisms and significance are poorly understood, it has the potential to lead to serious diagnostic difficulties and even confusions. ${ }^{12-18}$ The introduction of transcription factor expression assessment for diagnostic purposes only sparsely clarified lymphoma lineage determination. Moreover, recent findings indicate that transcription factors of either $\mathrm{B}^{19}$ or T-cell lineage ${ }^{20}$ are repeatedly aberrantly expressed in T- and B-cell lymphomas, respectively, representing a rather common phenomenon probably contributing to lymphomagenesis. In phenotypically equivocal cases, therefore, molecular investigation of immunoglobulin heavy chain (IgH)- and T-cell receptor gene rearrangements to establish the B- or T-cell histogenesis should also be considered, although cases with concurrent rearrangement of IgH- and T-cell receptor genes are reported with a frequency of approximately $10 \%$ for both B- and T-cell lymphomas, respectively. ${ }^{21,22}$ Thus, lymphoma lineage determination should be based on a multimodal approach that considers morpho-, pheno- and genotypic characteristics.

Recently, we observed for the first time a BSAPpositive peripheral T-cell lymphoma, not otherwise 
specified, with monoclonal $T$-cell receptor $\gamma$-gene rearrangement. To assess the relative frequency of BSAP expression in mature T-cell lymphomas, we constructed and examined a tissue microarray consisting of 43 angioimmunoblastic T-cell lymphomas and peripheral T-cell lymphomas.

\section{Materials and methods}

\section{Cases}

Formalin-fixed, paraffin-embedded material from a right para- and intrascapular lesion excised from a 61-year-old male patient, to diagnose a primary bone tumor, was sent for a second opinion to the Bone Tumor Reference Center of the Swiss Society of Pathology at the Institute of Pathology at the University Hospital Basel (Switzerland).

For construction of the tissue microarray, 43 paraffin-embedded T-cell lymphoma tissue samples from various institutions were selected. The cases consisted of 26 angioimmunoblastic T-cell lymphomas (16 male and ten female patients, mean age 70 years) and 17 peripheral T-cell lymphomas (ten male and 7 female patients, mean age 68 years).

\section{Tissue Microarray Construction}

Construction of the tissue microarray was performed as described previously. ${ }^{23}$ One core per case was arrayed. Validation was performed by comparison of the staining results for CD5, CD20 and BSAP obtained on the tissue microarray to conventional tissue sections of five cases.

\section{Immunohistochemistry}

Biopsy slides were processed on an automated immunostainer (Nexes, Ventana, Tucson, AZ, USA), except for BSAP-, CD4-, CD19 stains, as well as BSAP/CD5 double stains, which were performed manually. The tissue microarray was stained manually. The streptavidin-biotin peroxidase technique with diaminobenzidine as chromogen and the alkaline phosphatase/anti-alkaline phosphatase (APAAP) method with fast red as chromogen were applied. The primary antibodies were diluted in a $1 \%$ solution of bovine serum albumin in PBS $(\mathrm{pH}$ 7.4). Automatic incubation lasted $32 \mathrm{~min}$ at $37^{\circ} \mathrm{C}$, manual incubation $120 \mathrm{~min}$ at room temperature. For double stains, heat-induced antigen retrieval in citrate buffer ( $\mathrm{pH}$ 6.0) for $10 \mathrm{~min}$ was performed and the slides were then incubated for 120 min with the primary anti-BSAP antibody and with the peroxidase-bound secondary antibody, and stained with diaminobenzidine; a second incubation for $120 \mathrm{~min}$ with the primary anti-CD5 antibody and APAAP detection were subsequently carried out. Primary antibodies used, their dilutions and antigen retrieval conditions are listed in Table 1.

The relative proportion (percentage) of positively staining tumor cells was evaluated and cut-off values of $\geq 30 \%$ positivity for CD3, CD4, CD5 and CD8 were considered. In the case of Ki-67, the entire relative proportion of positively staining cell nuclei was considered. All slides were carefully examined on a double-headed microscope. In equivocal cases, consecutive slides were studied to exclude aberrant expression of BSAP on T-cell populations.

\section{T-cell receptor $\gamma$ - and IgH Gene Rearrangement Analysis}

The total DNA from the paraffin-embedded BSAPpositive peripheral T-cell lymphoma was extracted and multiplex polymerase chain reaction (PCR) analysis of $I g H$ - and $\mathrm{T}$-cell receptor $\gamma$ gene rearrangements was performed as described previously. ${ }^{24}$

Table 1 Antibodies applied and index BSAP-positive peripheral T-cell lymphoma case phenotype

\begin{tabular}{|c|c|c|c|c|}
\hline Antigen & Dilution & Retrieval & Source & Phenotype (, $\pm \%$ positive cells) \\
\hline CD1a & $1: 25$ & Citrate buffer, $\mathrm{pH}$ 6.0, microwave oven $10 \mathrm{~min}$ & Novocastra & - \\
\hline CD2 & $1: 25$ & Citrate buffer, $\mathrm{pH}$ 6.0, microwave oven $10 \mathrm{~min}$ & Novocastra & $+(80)$ \\
\hline CD3 & Prediluted & Citrate buffer, pH 6.0, microwave oven $10 \mathrm{~min}$ & DAKO & $+(30)$ \\
\hline CD4 & $1: 20$ & Citrate buffer, $\mathrm{pH}$ 6.0, microwave oven $10 \mathrm{~min}$ & Neomarkers & $+(100)$ \\
\hline CD5 & Prediluted & Citrate buffer, pH 6.0, microwave oven $10 \mathrm{~min}$ & CellMarque & $+(100)$ \\
\hline CD7 & $1: 25$ & Citrate buffer, pH 6.0, microwave oven 10 min & Novocastra & $+(90)$ \\
\hline CD8 & $1: 25$ & Citrate buffer, pH 6.0, microwave oven $10 \mathrm{~min}$ & Novocastra & - \\
\hline CD19 & $1: 800$ & Citrate buffer, pH 6.0, microwave oven $30 \mathrm{~min}$ & Serotec & $+(15)$ \\
\hline CD20 & Prediluted & Citrate buffer, pH 6.0, microwave oven 10 min & DAKO & - \\
\hline CD30 & Prediluted & EDTA, pH 8.0, microwave oven $10 \mathrm{~min}$ & Medite & $+(50)$ \\
\hline CD45RA & Prediluted & Citrate buffer, $\mathrm{pH}$ 6.0, microwave oven $10 \mathrm{~min}$ & Ventana & - \\
\hline CD56 & $1: 100$ & Citrate buffer, $\mathrm{pH}$ 6.0, microwave oven $10 \mathrm{~min}$ & Novocastra & - \\
\hline CD79a & $1: 25$ & Citrate buffer, pH 6.0, microwave oven $10 \mathrm{~min}$ & Neomarkers & - \\
\hline ALK-1 & $1: 100$ & Citrate buffer, $\mathrm{pH}$ 6.0, microwave oven $10 \mathrm{~min}$ & Novocastra & - \\
\hline BSAP (PAX-5) & $1: 50$ & Citrate buffer, pH 6.0, microwave oven $10 \mathrm{~min}$ & Biocare & $+(60)$ \\
\hline LMP-1 of EBV & $1: 25$ & EDTA, $\mathrm{pH}$ 8.0, microwave oven $10 \mathrm{~min}$ & CellMarque & - \\
\hline MIB-1 (Ki-67) & Prediluted & Citrate buffer, $\mathrm{pH}$ 6.0, microwave oven $10 \mathrm{~min}$ & DAKO & $+(75)$ \\
\hline TdT & Prediluted & Citrate buffer, pH 6.0, microwave oven $10 \mathrm{~min}$ & Ventana & - \\
\hline
\end{tabular}



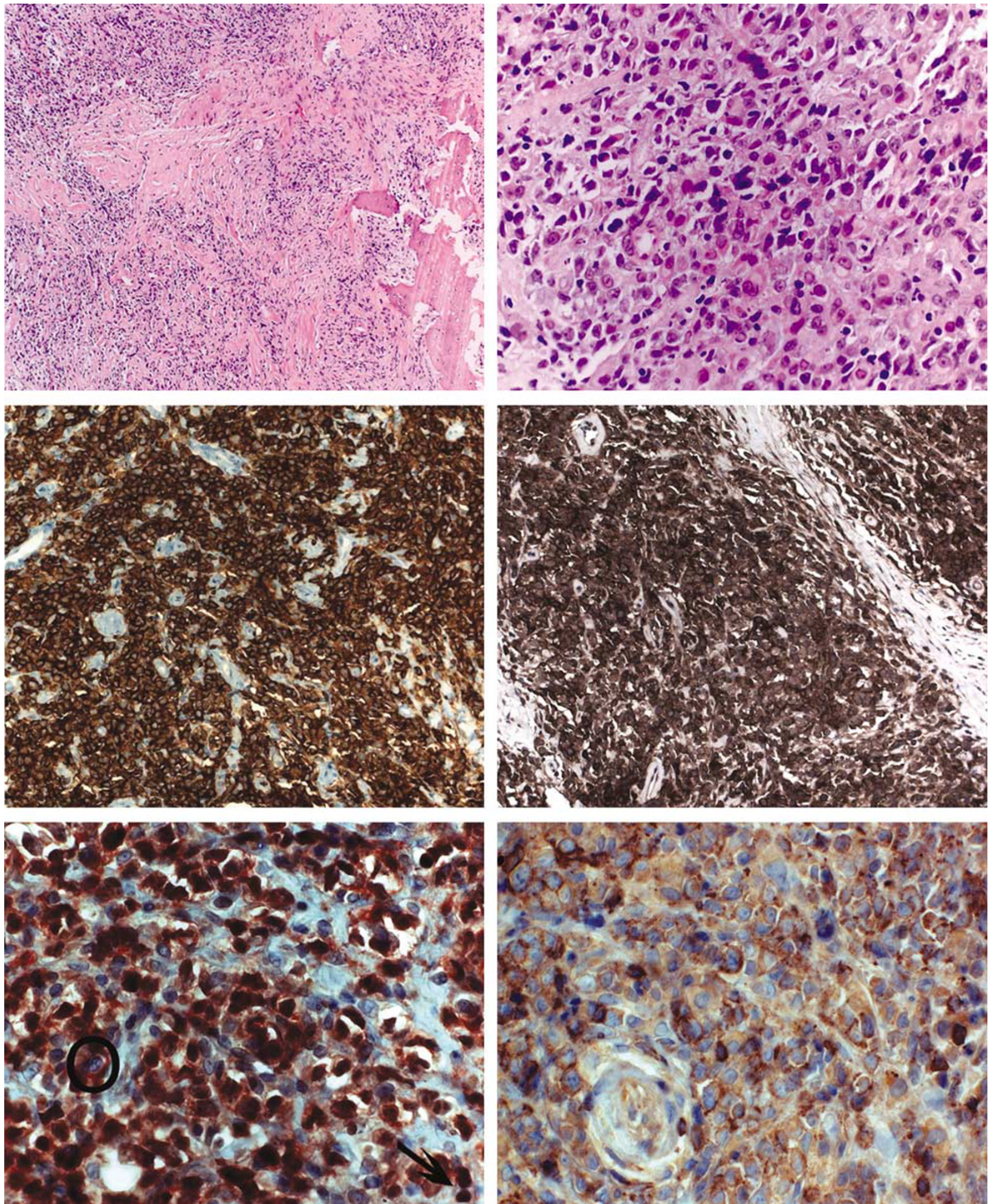

Figure 1 Upper left: Periscapular soft tissue diffusely infiltrated by tumor cell sheets surrounded by collagen bands and crossed by prominent vessels, destroying the adjacent cortical bone, H\&E-stain, $\times 50$ magnification. Upper right: Detailed view of tumor cell sheets consisting of medium-sized lymphoid cells with broad eosinophilic to pale cytoplasms and large irregular nuclei with prominent nucleoli, H\&E-stain, $\times 400$ magnification. Middle left: Expression of CD5 by T-cell lymphoma cells, immunoperoxidase stain, $\times 200$ magnification. Middle right: Expression of CD4 by T-cell lymphoma cells, immunoperoxidase stain, $\times 200$ magnification. Lower left: Coexpression of CD5 (membranous/submembranous, red) and BSAP-1 (nuclear, brown) by T-cell lymphoma. Note colocalization of stains in the majority of cells as well as functioning internal negative controls: Isolated CD5-negative/BSAP-positive reactive B-cells (arrow) and CD5-positive/BSAP-negative T-cells (encircled). Immunoperoxidase and APAAP/fast red stains, $\times 630$ magnification. Lower right: Expression of CD19 in T-cell lymphoma cells in an area with abundant tumor cells in consecutive sections, immunoperoxidase stain, $\times 630$ magnification (lower right). 


\section{Results}

\section{Morphology of the BSAP-Positive Peripheral T-Cell Lymphoma}

The periscapular soft tissue showed a diffuse infiltration of medium-sized lymphocytes with broad eosinophilic to pale cytoplasms and large, irregular, at times gyrated nuclei with prominent nucleoli (Figure 1, upper panels). Isolated Hodgkin's-like tumor cells as well as a low number of intermingled eosinophils and background small lymphocytes, were also present. Tumor cell sheets were surrounded by thickened collagen bands and crossed by prominent vessels. The adjacent periosteum was thickened with an increased amount of osteoclasts.

\section{Phenotypic and Genotypic Analysis of the BSAP-positive Peripheral T-Cell Lymphoma}

Immunophenotypic tumor cell characteristics are summarized in Table 1 and to a part shown on Figure 1. This peripheral T-cell lymphoma expressed CD4 and CD5 in 100\% of cells and showed incomplete antigen losses of CD2 (expression in 80\%), CD3 (expression in 30\%) and CD7 (expression in $90 \%$ ), complete loss of CD45RA, and lacked expression of CD79a, but was partially positive for CD19. Double stains highlighted coexpression of nuclear BSAP- and membranous CD5 signals (Figure 1 , lower left). Clonal T-cell receptor $\gamma$-, but not IgH gene rearrangements, were detected by PCR (Figure 2).

\section{Tissue Microarray Quality and Validation}

All 43 arrayed samples were evaluable for morphological examination and also for assessment of CD4. The number of evaluable cases for determination of other markers varied from slide to slide, but was at least $40(93 \%)$, which is in range with our experience in other lymphoma tissue microarrays. ${ }^{23}$ Validation of the tissue microarray with antibodies for CD5, CD20 and BSAP showed a perfect agree- ment of the staining results between conventional tissue sections and the tissue microarray.

\section{Expression of BSAP in Angioimmunoblastic/ Peripheral T-Cell Lymphoma Tissue Microarray}

The results for expression of CD3, CD4, CD5, CD8 and Ki-67, as well as BSAP and CD20 and the frequency of CD4/CD8 double-positive/doublenegative cases on our tissue microarray population, are shown in Table 2. The amount of non-neoplastic $\mathrm{B}$ cells varied among the arrayed T-cell lymphomas, with a mean of $23 \pm 20 \%$ CD20-positive B cells and $9 \pm 11 \%$ BSAP-positive B cells. We were not able to identify any BSAP-expressing T-cell lymphoma.

\section{Discussion}

Herein, we report for the first time the rare expression of BSAP in an otherwise morphologically, immunophenotypically and genotypically classic peripheral T-cell lymphoma. Previously published analyses of 67 mature T-lineage neoplasms, ${ }^{3,25}$ as well as our systemic tissue microarray screening of further 43 cases, did not detect any additional BSAP-positive mature T-cell lymphoma, indicating the identification of an exceptionally rare phenomenon. Importantly, except for BSAP, ${ }^{3,25}$ other functional B-cell-associated transcription factors, such as BOB-1, OCT-1, OCT-2 and BCL- $6,{ }^{19,26}$ have been detected in $30-80 \%$ of mature T-cell lymphomas in a substantial proportion of the tumor cells. On the other hand, BSAP expression has rarely been observed on immature T-cell neoplasms, including one T-lymphoblastic lymphoma and three T-acute lymphoblastic leukemia cases. ${ }^{25}$ Importantly in that context, in experimental mice models, knockin experiments with ectopic BSAP expression, under the control of the $\mathrm{IgH}$ locus in thymocytes, can also lead to the development of (immature) T-lymphoblastic lymphomas. ${ }^{27}$

In addition to its functional importance for B-cell development and identity maintenance, BSAP appears to be involved in B-cell lymphomagenesis in a particular subset of aggressive diffuse large B-cell

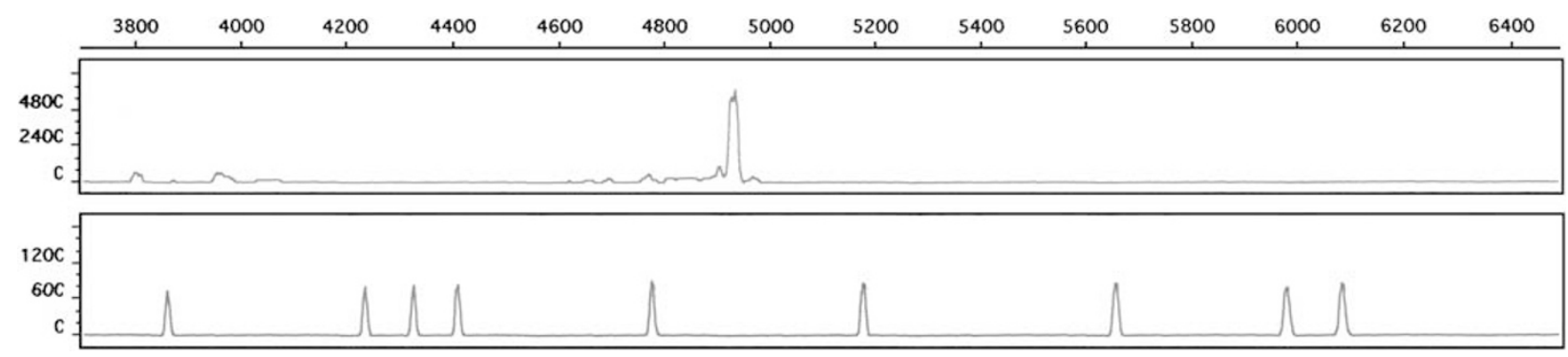

Figure 2 Analysis of BSAP-positive peripheral T-cell lymphoma for clonal IgH-and T-cell receptor $\gamma$-gene rearrangements. Fragments are aligned by size, as indicated above the upper panel. Upper panel: Peak in the T-cell receptor $\gamma$-specific size range, indicating a clonal rearrangement. Lower panel molecular weight markers. 
lymphomas ${ }^{28}$ and probably in some lymphoplasmacytic lymphomas carrying the $t(9 ; 14),{ }^{29}$ although the latter is controversial in the literature. ${ }^{30}$ Contrary to the assumption that BSAP, as a gene expressed exclusively in B- and not T-lymphocytes, might have no role in T-cell lymphomagenesis, experimental evidence showed that aberrant BSAP expression in thymocytes drives malignant transformation and, surprisingly, that the T-cell lineage, at least in vitro, is particularly prone to the oncogenic potential of BSAP. ${ }^{27}$ Our single case suggests that BSAP might also play a role in in vivo T-cell lymphomagenesis not only in immature, but also in mature T-cell lymphomas. Interestingly, in non-lymphoid hematological neoplasms, BSAP is expressed in $\mathrm{t}(8 ; 21)$ acute myelogenous leukemia, where similar to its function in developing B-cells, it upregulates its major transcriptional targets, CD79a and CD19. ${ }^{31}$ The present peripheral T-cell lymphoma case did not express CD79a, but CD19, indicating at least partial functional activity of BSAP.

Considering the diagnostic utility of transcription factor expression, particularly of BSAP, their pleiotropic biological functions in histogenetically different cells should be taken into account. The existence of rare BSAP-positive peripheral T-cell lymphoma underlines the importance of a multimodal approach in lymphoma lineage determination, which should be based on a broad immunohistochemical panel encompassing both surface/cytoplasmic (eg CD1a, CD2, CD3, CD5, CD19, CD20, CD79a) and nuclear antigens (eg BSAP, OCT-2, BOB-1 $)^{2,32}$ and, in selected cases, on genotypic analyses.

In summary, BSAP can probably contribute to T-cell lymphomagenesis not only in vitro, but also in vivo. It can be rarely expressed on peripheral T-cell lymphoma, thus its detection on lymphoid malignancies should not be considered definitively lineage specific.

\section{Acknowledgements}

We are indebted to Professor Dr med G Cathomas (Kantonspital Liestal, Switzerland), Professor Dr med F Offner (Landeskrankenhaus Feldkirch, Austria), Professor Dr med HJ Altermatt (Pathologie Länggasse, Bern, Switzernland) and Dr med U Wagner (Viollier AG, Basel, Switzerland) who contributed tissue for the tissue microarray construction. We thank Professor Dr med W Jochum (Department of Pathology, University Hospital Zürich, Switzerland) for critically reading the manuscript, and MK Occhipinti-Bender for editorial assistance.

\section{Disclosure/conflict of interests}

No conflicts of interests to declare. 


\section{References}

1 Berthold D, Ghielmini M. Treatment of malignant lymphoma. Swiss Med Wkly 2004;134:472-480.

2 Jaffe ES, Harris NL, Stein H, et al. Pathology and Genetics of Tumours of the Haematopoietic and Lymphoid System. IARC Press: Lyon, 2001.

3 Torlakovic E, Torlakovic G, Nguyen PL, et al. The value of anti-pax-5 immunostaining in routinely fixed and paraffin embedded sections: a novel pan pre-B and B-cell marker. Am J Surg Pathol 2002;26: 1343-1350.

4 Adams B, Dorfler P, Aguzzi A, et al. Pax-5 encodes the transcription factor BSAP and is expressed in B lymphocytes, the developing CNS, and adult testis. Genes Dev 1992;6:1589-1607.

5 Delogu A, Schebesta A, Sun Q, et al. Gene repression by Pax5 in B cells is essential for blood cell homeostasis and is reversed in plasma cells. Immunity 2006;24:269-281.

6 Nutt SL, Eberhard D, Horcher M, et al. Pax5 determines the identity of $B$ cells from the beginning to the end of B-lymphopoiesis. Int Rev Immunol 2001;20:65-82.

7 Souabni A, Cobaleda C, Schebesta M, et al. Pax5 promotes B lymphopoiesis and blocks T cell development by repressing Notch1. Immunity 2002;17: 781-793.

8 Dong HY, Liu W, Cohen P, et al. B-cell specific activation protein encoded by the PAX-5 gene is commonly expressed in Merkel cell carcinoma and small cell carcinomas. Am J Surg Pathol 2005;29: 687-692.

9 Torlakovic E, Slipicevic A, Robinson C, et al. Pax-5 expression in nonhematopoietic tissues. Am J Clin Pathol 2006;126:798-804.

10 Stuart ET, Kioussi C, Aguzzi A, et al. PAX5 expression correlates with increasing malignancy in human astrocytomas. Clin Cancer Res 1995;1:207-214.

11 Babjuk M, Soukup V, Mares J, et al. Association of PAX5 expression with clinical outcome in patients with Ta T1 transitional cell carcinoma of the bladder. Urology 2006;67:756-761.

12 Kaleem Z, White G, Zutter MM. Aberrant expression of T-cell-associated antigens on B-cell non-Hodgkin's lymphomas. Am J Clin Pathol 2001;115:396-403.

13 Petitjean B, Jardin F, Joly B, et al. Pyothorax-associated lymphoma: a peculiar clinicopathologic entity derived from $B$ cells at late stage of differentiation and with occasional aberrant dual B- and T-cell phenotype. Am J Surg Pathol 2002;26:724-732.

14 Sun T, Akalin A, Rodacker M, et al. CD20 positive T cell lymphoma: is it a real entity? J Clin Pathol 2004; $57: 442-444$.

15 Tzankov A, Brunhuber $\mathrm{T}$, Gschwendtner A, et al. Incidental oral plasmablastic lymphoma with aberrant expression of CD4 in an elderly HIV-negative patient: how a gingival polyp can cause confusion. Histopathology 2005;46:348-350.

16 Tzankov A, Bourgau C, Kaiser A, et al. Rare expression of T-cell markers in classical Hodgkin's lymphoma. Mod Pathol 2005;18:1542-1549.

17 Yao X, Teruya-Feldstein J, Raffeld M, et al. Peripheral T-cell lymphoma with aberrant expression of CD79a and CD20: a diagnostic pitfall. Mod Pathol 2001;14:105-110.
18 Went P, Agostinelli C, Gallamini A, et al. Marker expression in peripheral T-cell lymphoma: a proposed clinical-pathologic prognostic score. J Clin Oncol 2006;24:2472-2479.

19 Marafioti T, Ascani S, Pulford K, et al. Expression of B lymphocyte-associated transcription factors in human T-cell neoplasms. Am J Pathol 2003;162:861-871.

20 Dorfman DM, Hwang ES, Shahsafaei A, et al. T-bet, a T-cell associated transcription factor, is expressed in a subset of B-cell lymphoproliferative disease. Am J Clin Pathol 2004;122:292-297.

21 Kazakov DV, Kutzner H, Palmedo G, et al. Primary cutaneous lymphoproliferative disorders with dual lineage rearrangement. Am J Dermatopathol 2006;28: 399-409.

22 Vergier B, Dubus P, Kutschmar A, et al. Combined analysis of $\mathrm{T}$ cell receptor gamma and immunoglobulin heavy chain gene rearrangements at the single-cell level in lymphomas with dual genotype. J Pathol 2002;198:171-180.

23 Tzankov A, Went P, Zimpfer A, et al. Tissue microarray technology: principles, pitfalls and perspectiveslessons learned from hematological malignancies. Exp Gerontol 2005;40:737-744.

24 Meier VS, Rufle A, Gudat F. Simultaneous evaluation of $\mathrm{T}$ - and B-cell clonality, $\mathrm{t}(11 ; 14)$ and $\mathrm{t}(14 ; 18)$, in a single reaction by a four-color multiplex polymerase chain reaction assay and automated high-resolution fragment analysis: a method for the rapid molecular diagnosis of lymphoproliferative disorders applicable to fresh frozen and formalin-fixed, paraffin-embedded tissues, blood, and bone marrow aspirates. Am J Pathol 2001;159:2031-2043.

25 Zhang X, Lin Z, Kim I. Pax5 expression in nonHodgkin's lymphomas and acute leukemias. J Korean Med Sci 2003;18:804-808.

26 Kerl K, Vonlanthen R, Nagy M, et al. Alterations on the 5 ' noncoding region of the BCL-6 gene are not correlated with BCL-6 protein expression in $\mathrm{T}$ cell non-Hodgkin's lymphomas. Lab Invest 2001;81: 1693-1702.

27 Souabni A, Jochum W, Busslinger M. Oncogenic role of Pax5 in the T-lymphoid lineage upon ectopic expression from the immunoglobulin heavy-chain locus. Blood 2007;109:281-289.

28 Poppe B, De Paepe P, Michaux L, et al. PAX5/IGH rearrangement is a recurrent finding in a subset of aggressive B NHL with complex chromosomal rearrangements. Genes Chromosomes Cancer 2005;44: 218-223.

29 Iida S, Rao PH, Nallasivam $\mathrm{P}$, et al. The $\mathrm{t}(9 ; 14)$ (p13;q32) chromosomal translocation associated with lymphoplasmacytoid lymphoma involves the PAX-5 gene. Blood 1996;88:4110-4117.

30 Cook JR, Aguilera NI, Reshmi-Skarja S, et al. Lack of PAX5 rearrangements in lymphoplasmacytic lymphomas: reassessing the reported association with $\mathrm{t}(9 ; 14)$. Hum Pathol 2004;35:447-454.

31 Tiacci E, Pileri S, Orleth A, et al. PAX5 expression in acute leukemias: higher B-lineage specificity than CD79a and selective association with t(8;21)-acute myelogenous leukemia. Cancer Res 2004;64:7399-7404.

32 Chu PG, Loera S, Huang Q, et al. Lineage determination of CD20- B-Cell neoplasms: an immunohistochemical study. Am J Clin Pathol 2006;126:534-544. 